\title{
A participação dos conselhos locais de saúde na contratualização de metas na atenção primária à saúde: a experiência de Curitiba, PR
}

\author{
Local health councils participation in results-based contracting in primary \\ health care: the Curitiba, PR experience
}

La participación de los consejos locales de salud en la contratualización de
metas en la atención primaria a la salud: la experiencia de Curitiba, PR

Thabata Cristy Zermiani ${ }^{1}$

Rosane Souza Freitas ${ }^{1}$

Huáscar Fialho Pessali ${ }^{1}$

Rafael Gomes Ditterich ${ }^{1}$

\begin{abstract}
Recebido em 07/05/2018; revisado e aprovado em 14/03/2019; aceito em 08/04/2018
\end{abstract}
DOI: http://dx.doi.org/10.20435/inter.v0i0.1971

\begin{abstract}
Resumo: Objetiva-se analisar a participação dos Conselhos Locais de Saúde na contratualização de metas e no processo do trabalho na Atenção Básica em Curitiba, PR. Este estudo reproduziu a metodologia proposta em 2005 pelo Banco Mundial, sob o enfoque dos bens democráticos de Smith (2009). Constata-se que os Conselhos participam parcialmente na discussão das metas, no conhecimento e acompanhamento, mas não se envolve na negociação. Os Conselhos contribuem para o desenvolvimento do trabalho nas suas Unidades. Palavras-chave: atenção primária à saúde; bens democráticos; conselho local de saúde; contratos; gestão em saúde.
\end{abstract}

Abstract: This study analyzes the Local Health Councils participation in the agreement of goals, and in the work process in the Basic Attention in Curitiba, PR. This study reproduces the methodology proposed in 2005 by the World Bank, using the framework of democratic goods proposed by Smith (2009). The Councils take part in the discussion of goals, in acknowledging and monitoring the attainment of targets, but do not get involved in negotiating. The Councils help to improve the work in their respective healthcare units.

Keywords: primary health care; democratic goods; local health council; contracts; health management.

Resumen: Se pretende analizar la participación de los Consejos Locales de Salud en la pactación de metas y en el proceso del trabajo en las Unidades de Salud en Curitiba, PR. Este estudio reprodujo la metodología propuesta en 2005 por el Banco Mundial bajo el enfoque de los bienes democráticos de Smith (2009). Se constata que los Consejos participan parcialmente en la discusión de las metas, en el conocimiento y seguimiento, pero no en la negociación. Los Consejos contribuyen al desarrollo del trabajo en sus Unidades. Palabras clave: atención primaria a la salud; bienes democráticos; consejo local de salud; contratos; gestión de la salud.

\section{INTRODUÇÃO}

No Brasil, a ênfase na participação popular foi dada a partir do movimento da Reforma Sanitária, no início dos anos 1970, o qual lutava por uma nova roupagem nas práticas de saúde, com o intuito de universalizar seu acesso e transformá-la em um direito de todos. A 8 a Conferência Nacional de Saúde, realizada em 1986, foi um marco nesse contexto. Contando com grande envolvimento da população, dela saíram propostas de novas diretrizes para as políticas de saúde em âmbito nacional, incluindo a participação social no processo de formulação, planejamento, gestão, execução e avaliação das ações e estratégias de saúde. Propôs-se também a composição de um novo Conselho Nacional de Saúde e a criação de conselhos regionais, estaduais e municipais, todos com representação de entidades da sociedade civil (BRASIL, 2006).

\footnotetext{
${ }^{1}$ Universidade Federal do Paraná (UFPR), Curitiba, Paraná, Brasil.
} 
A Reforma Sanitária conviveu com a ditadura militar, período marcado pelo proibicionismo e repressão. Houve um intenso momento de mobilizações e lutas sociais em prol da efetivação da cidadania, o que culminou na promulgação da Constituição "Cidadã" de 1988. Assim, a participação social passou da condição de proibição para a de direito, criando-se mecanismos de controle social sobre as políticas públicas (BRAVO; CORREIA, 2012).

Corroborando com a Constituição, a Lei n. 8.080/90, que dispõe sobre condições, organização e funcionamento dos serviços de saúde, estabelece os princípios doutrinários e organizativos do Sistema Único de Saúde (SUS): universalidade no acesso, integralidade na assistência prestada à comunidade, equidade, descentralização, participação social, regionalização e hierarquização (BRASIL, 1990a). Já a Lei n. 8.142/90 dispõe especificamente sobre o controle social na gestão do SUS, bem como sobre as transferências de recursos financeiros. Define, no seu Art. 1으, que todos os entes federativos contarão com a Conferência de Saúde e com o Conselho de Saúde como instâncias colegiadas. Os conselhos têm caráter permanente e deliberativo, atuam na formulação de estratégias e no controle da execução da política de saúde na instância correspondente, inclusive nos aspectos econômicos e financeiros (BRASIL, 1990b).

A Resolução n. 333, de 2003, do Conselho Nacional de Saúde (CNS), é um dos principais documentos regulamentadores dos Conselhos de Saúde. Ela aprova as diretrizes para criação, reformulação, estruturação e funcionamento destes. Sobre sua composição, estabelece uma representação paritária entre os usuários e demais membros, que são os trabalhadores de saúde, o governo e os prestadores de serviços de saúde. O presidente e demais cargos são eleitos em reunião plenária. Cada conselho de saúde possui seu regimento interno próprio, cujas competências são estabelecidas pela Resolução. Entre elas, destacam-se: promover mobilização contínua em prol do controle social no SUS; discutir e elaborar propostas das e para as conferências de saúde; participar da formulação e controle da execução da política de saúde; fiscalizar, acompanhar e avaliar ações, propostas e serviços da saúde; promover ações de informação e comunicação sobre saúde e sobre os conselhos; dentre outras (BRASIL, 2003). Mais recentemente, a Resolução 453 de 2012, confirmou o papel do Conselho e estabeleceu suas principais diretrizes, abordando aspectos relacionados à sua organização, ao seu funcionamento e às suas competências (LOPES; SILVA; MARTINS, 2016).

Além dos Conselhos Municipais de Saúde, alguns territórios possuem os Conselhos Locais de Saúde (CLS), os quais são organizados em nível local. Os CLS estão vinculados a uma Unidade de Saúde e são constituídos por representantes de usuários de sua área de abrangência, trabaIhadores do próprio serviço e gestores do SUS. Dessa forma, tais Conselhos "[...] possibilitam a proximidade da comunidade da dinâmica dos serviços de saúde da unidade e a interação com as demais organizações do bairro. Por esta razão são considerados como componentes estratégicos da gestão participativa" (NOGUEIRA et al., 2008, p. 106).

Os conselhos participam dos processos de discussão, formulação e fiscalização das políticas de saúde, sendo ferramentas para colocar em prática os direitos e romper com as tradicionais formas de gestão. "[...] potenciais capacitores dos sujeitos sociais para processos participativos mais amplos e de interlocução ético-política com o Estado" (SALIBA et al., 2009, p. 1371). A participação popular confere maior transparência e legitimidade às políticas de saúde, além de um comprometimento coletivo com a gestão do SUS (BRASIL, 2009). 


\subsection{Bens democráticos de Smith}

Os conselhos, incluindo os de saúde, são considerados inovações democráticas, pois têm sido projetadas com a finalidade de ampliar e aprofundar a participação dos cidadãos no processo de tomada de decisão política (SMITH, 2009). A fim de possibilitar a comparação qualitativa entre as diferentes inovações, Smith (2009), em sua obra Democratic Innovations: Designing Institutions for Citizen Participation, propôs um quadro analítico que se fundamenta na forma e intensidade com que elas atendem a qualidades desejáveis ou bens esperados das instituições democráticas. São considerados bens essencialmente democráticos: a inclusão, o controle popular, o julgamento ponderado e a transparência; e são bens institucionais: a eficiência e o potencial de transferência.

A inclusão refere-se à maneira como a igualdade política é alcançada em relação à presença e à voz. Dessa forma, ao analisar esse bem, é necessário considerar o mecanismo de seleção, os incentivos empregados para motivar o engajamento e a participação de diferentes grupos sociais, e se o desenho institucional proporciona aos envolvidos a oportunidade de expressar suas opiniões. O controle popular avalia o grau de influência dos participantes nos diferentes aspectos do processo de tomada de decisão. Por vezes, a participação é limitada a questões consideradas seguras, ou ainda utilizada apenas para confirmar decisões tomadas em outros momentos (SMITH, 2009).

O julgamento ponderado envolve a compreensão dos aspectos técnicos da questão em análise e das perspectivas dos demais participantes. O cidadão deve ser capaz de se colocar no lugar dos outros, indo além de suas condições subjetivas privadas e desenvolvendo uma mentalidade ampliada. A transparência reflete a apresentação das ações e do processo deliberativo tanto para os participantes como para o público em geral. Deve haver, portanto, transparência interna e externa. A eficiência se refere aos custos que a participação pode impor aos cidadãos e às autoridades públicas. O custo para o indivíduo participar e o custo para o setor público fazer funcionar a instituição democrática em questão são condicionantes da viabilidade da inovação proposta. Por fim, o potencial de transferência indica em que medida os elementos do desenho podem ser replicados em diferentes contextos políticos (SMITH, 2009). O potencial de transferência não será avaliado neste trabalho.

O autor destaca que os bens abordados não consistem em uma lista definitiva, mas sim em componentes que podem ser esperados de instituições ou inovações. Ressalta-se ainda que é pouco provável que qualquer desenho institucional realize, de forma plena, todos esses bens. As instituições podem alcançá-los de diferentes maneiras e em diferentes combinações (SMITH, 2009).

\subsection{A contratualização de resultados na Atenção Primária à Saúde em Curitiba, PR}

Com a expansão e reorganização da Atenção Primária à Saúde (APS), os municípios têm adotado diferentes modelos de gestão. Dentre as ferramentas utilizadas, destaca-se a contratualização (DITTERICH; MOYSÉS; MOYSÉS, 2012). Esta envolve a definição de metas que norteiam as ações desenvolvidas, o estabelecimento dos meios para atingi-las, o monitoramento e avaliação das ações, e um sistema de incentivo para mobilizar o indivíduo em direção aos objetivos propostos (ARAÚJO, 2010).

No município de Curitiba, em 2002, foi proposta a contratualização na APS, com a finalidade de ampliar a participação, os acordos e a responsabilidade mútua entre os gestores, as equipes de saúde e a comunidade. Em 2003, a contratualização foi implantada por meio do instrumen- 
to denominado Termo de Compromissos (Tercom), em todas as Unidades Básicas de Saúde do município (AZEVEDO; FAORO; XAVIER, 2013).

O Tercom é firmado anualmente entre as equipes de saúde, as autoridades sanitárias locais, os supervisores distritais e o secretário municipal de saúde. Ao longo do processo, há também a contratualização com os Conselhos Locais de Saúde. Essa ferramenta de gestão tem como anexo o Plano Operativo Anual (POA)- uma planilha composta por indicadores, metas pactuadas para cada nível institucional e fontes para monitoramento (AZEVEDO; FAORO; XAVIER, 2013). Em Curitiba, o Conselho de Saúde é regulamentado pela Lei Municipal 7.631/91, que autoriza sua constituição, e a da Conferência Municipal da Saúde, dentre outras providências (CURITIBA, 1991).

Em 2005, o Banco Mundial desenvolveu uma pesquisa sobre inovações em gestão no Brasil, incluindo a gestão dos cuidados primários à saúde em Curitiba. Nesse município, foi feito um levantamento da percepção dos servidores que atuavam em suas unidades de saúde sobre o uso e aplicabilidade do contrato interno de gestão. A pesquisa identificou que a participação dos Conselhos é positiva tanto para a contratualização de metas, como para o processo de trabalho nas Unidades de Saúde, mas que isso acontece de forma limitada (WORLD BANK, 2006). Isso torna importante estudar o papel desempenhado pelos Conselhos de Saúde em tais aspectos.

Diante do exposto, o objetivo deste estudo é analisar a percepção dos servidores municipais da saúde sobre a participação dos CLS na contratualização de metas do Tercom e do POA, bem como sobre sua contribuição no processo do trabalho nas Unidades de Saúde de Curitiba. Essa análise será realizada com base nos bens democráticos listados por Smith (2009): inclusão, controle popular, julgamento ponderado e eficiência.

\section{METODOLOGIA}

Este artigo é um estudo de caso descritivo e de análise quantitativa, e reproduz, na pesquisa de campo, a metodologia empregada em 2005 pelo Banco Mundial (WORLD BANK, 2006). Em parceria com a Secretaria Municipal de Saúde, foram entregues questionários estruturados para os servidores municipais da saúde (autoridades sanitárias locais e profissionais de saúde da atenção básica) pré-selecionados pelo Cadastro Nacional de Estabelecimentos de Saúde (CNES) em 34 Unidades de Saúde do município de Curitiba, entre os meses de agosto e novembro de 2014.

Os instrumentos de coleta de dados foram cedidos à Autoridade Sanitária Local (ASL) de cada Unidade de Saúde, sendo esta convidada a participar da pesquisa. A ASL foi também responsável por disponibilizar os questionários aos profissionais de saúde de nível superior (enfermeiro, médico, cirurgião-dentista, entre outros) atuantes nas respectivas unidades, para o seu preenchimento de forma voluntária, além da assinatura do Termo de Consentimento Livre e Esclarecido (TCLE). A categoria profissional específica foi considerada irrelevante nesse processo. Posteriormente os TCLE e os questionários foram recolhidos em data previamente agendada por um dos pesquisadores envolvidos. Ao todo 148 servidores responderam ao questionário, sendo 22 ASL e 126 profissionais de saúde da atenção primária.

Ao processar a base de dados, foram excluídas da análise as entrevistas realizadas com as ASL e os profissionais de saúde que apresentavam menos de um ano de atuação nas Unidades de Saúde. Essa exclusão justifica-se pela necessidade de os profissionais participantes terem se apropriado do sistema de avaliação do desempenho, com um mínimo de tempo de serviço, e 
de terem recebido ao menos uma avaliação anualizada de desempenho, para poder interpretar e responder aos itens pesquisados. Vale enfatizar que a ASL de cada unidade participa obrigatoriamente do CLS, porém a participação dos profissionais de saúde é opcional, Nesta pesquisa, não houve distinção daqueles que são membros ou não dos conselhos.

O instrumento de coleta é composto por 25 questões de múltipla escolha. Dentre elas, foram selecionadas as que abordavam a contribuição dos CLS na contratualização de metas e resultados presentes no Tercom e no POA, e o processo de trabalho na Unidade de Saúde. A discussão dos resultados obtidos foi feita sob a ótica dos bens democráticos descritos por Graham Smith $^{9}$. O protocolo de pesquisa apresentado como pré-requisito à execução deste trabalho foi submetido à análise pelo Comitê de Ética em Pesquisa com Seres Humanos da Universidade Federal do Paraná, tendo sido aprovado em 7 de agosto de 2013 (CAAE 18110713.0.0000.0102), por estar em consonância com a resolução n. 466/12.

\section{RESULTADOS}

Ao investigar a percepção dos gestores e dos profissionais da saúde da APS acerca da contribuição do CLS para a contratualização de metas em Curitiba, por meio do Tercom e do POA, viu-se que 58,8\% consideram que o Conselho participa parcialmente na discussão dos objetivos gerais do Tercom. Sobre o envolvimento do Conselho na negociação das metas, 55,4\% dos servidores consideraram que isso nunca acontece ou que isso se dá de forma parcial (40,5\%). No que tange ao conhecimento e acompanhamento das metas pelo Conselho, a maioria considerou que isso acontece parcialmente (71,6\% e 67,6\%) (Tabela 1).

Tabela 1 - Percepção dos gestores e dos profissionais da saúde da atenção primária sobre a contribuição do Conselho Local de Saúde na contratualização de metas e resultados em Curitiba, PR

\begin{tabular}{ccc}
\hline \multicolumn{3}{c}{ CONTROLE SOCIAL, TERCOM E POA } \\
\hline Nunca & Parcialmente & Integralmente \\
\hline \multicolumn{3}{c}{ Participa na discussão de objetivos gerais } \\
& $87(58,8 \%)$ & $20(13,5 \%)$ \\
\hline $32(55,4 \%)$ & Envolve-se na negociação das metas \\
& $60(40,5 \%)$ & $6(4,1 \%)$ \\
$28(18,8 \%)$ & Conhece as metas & $14(9,5 \%)$ \\
$43(29 \%)$ & $106(71,6 \%)$ & $5(3,4 \%)$ \\
\hline
\end{tabular}

Fonte: Os autores (2016).

Os servidores de saúde envolvidos na pesquisa também foram questionados se o Conselho contribui ou não para o desenvolvimento do trabalho nas suas respectivas unidades. Nesse âmbito, $67,6 \%$ dos entrevistados afirmaram que o conselho colabora. Entre os que responderam sim, foi-lhes indagado sobre que tipo de contribuição o conselho de saúde proporciona, com algumas opções de resposta. 
De maneira mais enfática, para 89\% dos servidores de saúde entrevistados, a prestação de informações sobre a comunidade é a principal contribuição do Conselho. De modo relacionado, identificar os focos dos problemas da comunidade (62\%) e dar ideias sobre como aumentar a cobertura do atendimento (45\%) vêm em seguida como formas de colaboração mais importante dos conselhos. Ainda, a facilitação da busca ativa foi identificada por $25 \%$ dos entrevistados como um tipo de contribuição.

\section{DISCUSSÃO}

O contrato de gestão estabelece a divisão de responsabilidades, o monitoramento do desempenho e o retorno do processo de planejamento. Sua importância para os serviços de saúde é decorrente da natureza compartilhada do SUS e do estabelecimento de uma relação em que as metas a serem atingidas são determinadas por meio de um processo de negociação, com o propósito de melhor atender a população (TAVARES et al., 2013). Tais metas são quantitativas e expressas por indicadores de saúde, como por exemplo, a cobertura vacinal. Entretanto ainda são observados problemas de coordenação e supervisão dos contratos, descontinuidade na administração pública (TORRES, 2007), existência de metas pré-definidas não condizentes com o orçamento disponível, capacitação insuficiente dos profissionais envolvidos, falhas na negociação e inefetividade ou ausência de sistemas de avaliação e monitoramento (ESCOVAL, 2010).

O Tercom é uma ferramenta gerencial proposta para reduzir a distância entre a gestão estratégica e o centro operacional, ou seja, entre o planejamento e a implementação das ações, possibilitando a negociação e a adoção de compromissos pactuados. Para atingir tal fim, parte-se da premissa da corresponsabilidade entre os trabalhadores e o nível diretivo (DITTERICH; MOYSÉS; MOYSÉS, 2012). Isso torna mais relevante o envolvimento do controle social nos mecanismos e ferramentas gerenciais do SUS.

Marty (2012) destaca o incentivo à participação popular como um dos aspectos fundamentais da construção do SUS em Curitiba. Ela se deu, a princípio, por meio das Comissões de Saúde nas Unidades de Saúde, evoluindo para a constituição dos Conselhos Municipal, Distritais e Locais de Saúde. Os CLS participam também do processo de contratualização de metas do Tercom em Curitiba. A contratualização entre as Autoridades Sanitárias Locais, os Supervisores Distritais, o Secretário Municipal de Saúde e os Conselhos colabora para conferir transparência e controle social sobre a atuação dos profissionais de saúde (MARTY, 2012; 2009).

Ao analisar a opinião dos servidores da saúde sobre a participação do CLS na discussão dos objetivos gerais do Tercom, a maioria dos entrevistados avaliou haver uma participação parcial. Sobre o envolvimento do Conselho na negociação das metas, a maioria considerou que ele nunca acontece. Analisando esse resultado com base nos bens democráticos de Smith, observa-se que o controle popular está sendo atingido parcialmente.

Segundo Smith (2009), o controle popular avalia o nível de influência dos participantes nos vários aspectos do processo de tomada de decisão, incluindo a definição do problema, a análise e seleção das opções, e a implementação. Diante do exposto, vê-se que o controle popular tem sido verificado de forma limitada. Percebe-se que os membros do Conselho participam da discussão e seleção dos objetivos, ou seja, do reconhecimento dos problemas e da análise das opções existentes para solucioná-los; mas não estão envolvidos na definição e negociação das metas, o que corresponde à fase da implementação. 
Essa participação limitada pode decorrer da falta de julgamento ponderado, ou seja, da dificuldade em compreender os aspectos técnicos da questão em análise ou em considerar as necessidades daqueles que não estão envolvidos diretamente no Conselho, mas que são por ele representados. A participação de distintos segmentos de representação no Conselho é necessária para que sejam reconhecidas as necessidades de saúde da região, mas pode não ser suficiente. A deficiência do julgamento ponderado por parte dos conselheiros dificulta o debate e o estabelecimento de objetivos e metas de forma mutuamente fundamentada. O número de procedimentos estipulado, por exemplo, depende não apenas da necessidade local explicitada, mas também dos recursos humanos e financeiros disponíveis, bem como das razões técnicas de sua combinação, para que o fim proposto seja atingido. O desconhecimento parcial ou total desses elementos pode dificultar uma melhor ponderação dos julgamentos dos conselheiros não técnicos.

Essa percepção dos entrevistados sobre a limitada participação do Conselho na definição de objetivos e metas do Tercom aponta para outras limitações existentes, que afetam a participação ativa nos Conselhos e merecem atenção. É possível associá-la à precária inclusão dos trabalhadores e principalmente da população nos CLS, à falta de motivação, ou a dificuldades não técnicas em expressar suas opiniões nos espaços de debate. Costa e Vieira (2013, p. 256) notam que:

[...] apesar da paridade numérica com os outros segmentos, não há na sociedade civil uma paridade política. Isso tem como resultado uma representação de usuários que não consegue se articular e construir consensos em torno de suas demandas. O produto disso é que, no processo de escolha, a sociedade acaba sendo influenciada, quando não atropelada, pelos posicionamentos de outros segmentos, seja dos trabalhadores ou do governo.

Assim, apesar de a sociedade civil ter presença nos conselhos, sua opinião pode ser muito influenciada por profissionais de saúde ou gestores. E estes, participando ou não dos conselhos, são quem compõe o rol de pessoas que discutem sobre as metas que posteriormente serão firmadas. Portanto a concepção desse grupo acaba por prevalecer sobre a daquele. Isto suscita a possibilidade de o conhecimento específico das ASL funcionar como uma barreira instituída ao julgamento ponderado das pactuações, limitando a participação da sociedade civil a trazer informações.

O conhecimento parcial das metas pelo Conselho, identificado pela maioria dos entrevistados, reflete haver transparência e algum conhecimento para a formação do julgamento ponderado. De acordo com o Regimento Interno dos Conselhos Locais de Saúde de Curitiba, PR (CURITIBA, 2015), cabe ao Conselho deliberar sobre as ações prioritárias em saúde para a sua Unidade Municipal de Saúde em consonância com as diretrizes provenientes das Conferências Local, Distrital e Municipal de Saúde, bem como deliberar e aprovar o plano local de saúde em conformidade com o plano distrital e municipal de saúde. Conhecer as metas, portanto, é relevante para que as demais ações participativas da contratualização possam ser conduzidas de forma ponderada.

O acompanhamento das metas pelo Conselho é percebido por $67,6 \%$ dos entrevistados. O Regimento Interno dos Conselhos Locais de Saúde de Curitiba (CURITIBA, 2015) determina que eles devem acompanhar, avaliar e fiscalizar a execução dos serviços e ações oferecidos à população pelos atores integrantes do SUS. Para Marty (2009), o monitoramento do Contrato de Gestão consiste no exame contínuo ou periódico da realização de cada fase de ação em todos os 
níveis hierárquicos com o fim de possibilitar o desenvolvimento de medidas corretivas quando necessário. Já a avaliação tem o objetivo de conferir transparência aos Contratos de Gestão e sua revisão. O acompanhamento deve ser realizado de forma cotidiana, quadrimestral, anual e ao término da gestão. A avaliação ocorre em três ciclos anuais, ao fim de cada quadrimestre, por meio da análise de cada meta e indicador pactuado (MARTY, 2009). Em havendo acompanhamento e avaliação das metas, por princípio, fica clara a necessidade da participação e do controle popular através do Conselho em ambas as etapas. Isto viabiliza a mais frequente sensibilização dos profissionais de saúde, tanto para a proposição realista de metas, quanto para a atenção constante ao cumprimento delas.

Para que haja o acompanhamento das metas estabelecidas, é preciso que os Conselhos se apropriem também do bem democrático da transparência. Isto se dá por meio da apresentação das ações e do próprio processo deliberativo tanto para os participantes como para o público em geral. O regimento interno do Conselho Municipal de Saúde (CMS) de Curitiba (2015), no seu Art. 5으, define que uma de suas competências e atribuições é:

[...] divulgar as deliberações, resoluções, moções, recomendações e outros atos administrativos do Conselho Municipal, Distrital e Local de Saúde, bem como, ações de interesse público através de publicações impressas, como o jornal informativo do Conselho Municipal de Saúde, de periodicidade mensal e em meio eletrônico. (CURITIBA, 2015).

Espera-se de instituições participativas e deliberativas, como os Conselhos, por sua própria razão de ser, que exerçam controle sobre as decisões tomadas. Como afirmam Rolim, Cruz e Sampaio (2013, p. 142),

[...] busca-se assegurar que os gestores públicos se comprometam com a excelência na concepção e implementação dos programas, projetos, ações e serviços de saúde. De um lado, portanto, o controle tem um sentido de vigilância e responsabilização. Do outro, tem o sentido de efetividade e compromisso com a coisa pública.

Nesse quesito da contribuição dos Conselhos de Saúde para o desenvolvimento do trabaIho nas Unidades Básicas de Saúde, um percentual significativo dos entrevistados $(67,6 \%)$ tem a percepção de que isso de fato acontece.

Outro bem democrático elementar é a inclusão. Ela arregimenta a capacidade da instituição em contemplar a variedade de posições sociais interessadas e afetadas num campo de ação das políticas públicas (presença), bem como em engajá-la a expressar-se sem constrangimentos (voz). Este bem parece presente, de acordo com a maioria dos entrevistados. Sua percepção vem através da contribuição dos CLS em trazer informações sobre a comunidade. Para melhorar a qualidade de seu trabalho, é essencial às Unidades de Saúde conhecer bem seu território adscrito e as demandas nele emergentes (BRASIL, 2012). No entanto é plausível reconhecer que tal conhecimento é difícil de se obter e atualizar. Embora a pesquisa não possa afirmar que presença e voz do CLS sejam bens de amplo usufruto em termos absolutos, elas parecem pelo menos estar presentes o suficiente para ampliar o conhecimento das Unidades de Saúde. Assim, se o Conselho tem aproximação com a comunidade, conhece suas demandas, presta informações sobre estas para os serviços de saúde e é ouvido, espera-se que a execução do trabalho dentro destes possa ter maior resolutividade.

Em relação à identificação de focos de problemas, 62\% dos entrevistados a consideraram também como uma importante contribuição dos Conselhos para o trabalho das Unidades de 
Saúde. Isto demonstra que os conselheiros possuem bom vínculo com a população, bem como têm discernimento sobre a dinâmica do território, o que torna possível captar a causa das dificuldades apresentadas pela comunidade. Tal fato permite constatar que o bem democrático do juízo ponderado está presente nessas ações dos Conselhos. Isto ocorre devido à proximidade dos conselheiros com a comunidade, e pode ser também atribuído ao fato de muitos membros dos CLS pertencerem a própria comunidade, como é o caso dos representantes dos usuários.

Sobre a questão referente à contribuição dos conselheiros com ideias sobre como aumentar a cobertura no atendimento, $45 \%$ dos servidores de saúde identificaram como uma importante contribuição dos Conselhos. Entende-se como cobertura no atendimento de saúde "[...] a oferta sistematizada de serviços básicos de saúde que satisfaçam às necessidades de uma população determinada, [...] que garantam o acesso da população aos diferentes níveis de atendimento aos sistemas de serviços de saúde" (BRASIL, 2004).

É importante frisar que, na Resolução n. 333, fica definido que compete aos Conselhos "[...] atuar na formulação e no controle da execução da política de saúde, incluindo os seus aspectos econômicos e financeiros e propor estratégias para a sua aplicação aos setores público e privado" (BRASIL, 2003). É atribuição dos conselheiros, portanto, sugerir meios para que o acesso às políticas de saúde seja ampliado. Porém a contribuição do conselho nesse processo é percebida como importante por apenas alguns servidores, e isto pode estar atrelado ao fato de os conselheiros, muitas vezes, não possuírem conhecimento técnico sobre o financiamento e possíveis estratégias de atendimento, ou seja, a dificuldade em produzir juízo ponderado inibe maior/melhor participação neste âmbito.

No que tange à facilitação da busca ativa por parte dos conselheiros no trabalho desenvolvido nas Unidades de Saúde, apenas $25 \%$ dos entrevistados consideraram como um tipo de contribuição. A busca ativa é uma estratégia utilizada nos serviços de saúde que concerne na identificação de novos casos/demandas, bem como a busca de usuários que se distanciaram/ abandonaram seus tratamentos. A participação incipiente dos Conselhos nessas ações pode estar relacionada à falta de tempo desses representantes, ou até mesmo falta de recurso financeiro para possibilitar a busca ativa. Tal fato pode ser associado ao bem democrático da eficiência.

Diante do exposto, fica evidente que a participação se expressa na dinâmica social das mais distintas formas. Apesar das limitações inerentes a todo contexto do controle social, existem maneiras de superar algumas dificuldades, ou ao menos tentar entendê-las. Os bens democráticos podem representar o que se espera minimamente de instituições empenhadas na vontade popular. Os Conselhos de Saúde são de suma importância no processo de formulação e implementação das políticas públicas de saúde, então, contar com conselheiros empenhados na inclusão, no controle popular, no juízo ponderado e na eficiência, representa uma maior legitimidade para os Conselhos.

Assim, todo e qualquer indivíduo não deve eximir-se da capacidade e possibilidade que tem de participar das decisões públicas, tendo liberdade para questionar e lutar por ideais comuns. Gohn (2005) afirma que: "[...] não se muda a sociedade apenas com a participação no plano local, micro, mas é a partir do plano micro que se dá o processo de mudança e transformação na sociedade". Sendo assim, a mobilização é necessária desde as menores instâncias sociais, como por exemplo, os Conselhos Locais de Saúde, até o patamar que envolva o maior quantitativo de indivíduos e decisões. 


\section{CONSIDERAÇÕES FINAIS}

O controle social, relacionado com o envolvimento da sociedade nos processos de decisões, formulação e implementação das políticas públicas, apresenta grande relevância social e política. No âmbito da saúde, a participação popular possibilita uma maior vinculação da comunidade com a gestão do SUS, facilitando assim a identificação e a priorização de demandas emergentes na sociedade, garantindo, consequentemente, a efetivação do acesso à saúde mais universal, integral e equânime. Os Conselhos de Saúde podem ser considerados instituições democráticas que viabilizam esse vínculo, e a participação dos seus representantes nas pactuações da saúde devem ser incentivadas e garantidas, uma vez que a busca pela autonomia desses espaços de debates possibilitam o fortalecimento das políticas.

A análise da percepção de Autoridades Sanitárias e profissionais de saúde sobre o engajamento dos Conselhos Locais de Saúde nos processos de negociação do Tercom e POA reflete significativamente no papel que os conselheiros vêm desempenhando. Avaliar tais fatos à luz dos bens democráticos e institucionais sugeridos por Smith (2009) possibilita a identificação de aspectos que estão condizentes ou não com as reais competências e atribuições dos representantes dos Conselhos, expostos nas normativas jurídicas. Isto pode influenciar em possíveis ajustes e melhoras nesses processos.

Observou-se que, segundo a concepção dos servidores entrevistados, o Conselho está contribuindo, em parte, no processo de contratualização de metas e de trabalho nas Unidades de Saúde de Curitiba. Constatou-se, portanto, que, embora estejam sendo atingidos alguns dos bens democráticos sugeridos por Smith, isto não está se dando de forma integral, o que reflete a necessidade de ampliar o conhecimento dos conselheiros acerca das metas e indicadores pactuados no Tercom e no POA, para que possam participar de todo o processo de contratualização de forma ativa e consciente. Nesse sentido, destaca-se a importância da realização de cursos de capacitação que possibilitem o desenvolvimento do julgamento ponderado. Além disso, convém ressaltar a necessidade de realização de estudos futuros que sejam direcionados de forma exclusiva àqueles que estão diretamente envolvidos nos Conselhos Locais de Saúde, bem como de estudos com abordagem qualitativa, para aprofundar ainda mais o debate acerca desse assunto.

Diante dessa dinâmica social, o homem toma consciência de sua realidade, se organiza e assume posições de desafio e enfrentamento, na tentativa de minimizar problemas e/ou propor alternativas. Com efeito, a participação social, sendo cada vez mais consolidada, possibilitará, de maneira mais eficaz, políticas públicas voltadas para a garantia dos direitos dos cidadãos, pois o povo é quem pode discorrer com fidedignidade sobre as ações públicas em seu favor.

\section{REFERÊNCIAS}

ARAÚJO, M. A. D. Responsabilização pelo controle de resultados no Sistema Único de Saúde no Brasil. Revista Panamericana de Salud Publica, v. 27, n. 3, p. 230-6, 2010.

AZEVEDO, J. C. R.; FAORO, N. T.; XAVIER, E. A. Avaliação de desempenho: um instrumento de gestão e democratização nas relações de trabalho. In: BRASIL. Ministério da Saúde. Secretaria de Gestão do Trabalho na saúde (Org.). Prêmio InovaSUS: valorização de boas práticas e inovação na gestão do trabalho na saúde. 1. ed. Brasília, DF: Ministério da Saúde, 2013. p. 29-35.

BRASIL. Ministério da Saúde. Secretaria de Atenção à Saúde. Departamento de Atenção Básica. Política Nacional de Atenção Básica. Brasília: Ministério da Saúde, 2012. 
BRASIL. Ministério da Saúde. Secretaria-Executiva. Departamento de Apoio à Descentralização. O SUS no seu município: garantindo saúde para todos. 2. ed. Brasília: Ministério da Saúde, 2009.

BRASIL. Ministério da Saúde. Secretaria de Gestão Estratégica e Participativa. A construção do SUS: histórias da Reforma Sanitária e do Processo Participativo. Brasília: Ministério da Saúde, 2006.

BRASIL. Ministério da Saúde. Glossário do Ministério da Saúde: projeto de terminologia em saúde. Brasília: Ministério da Saúde, 2004.

BRASIL. Ministério da Saúde. Resolução n. 333, de 4 de novembro de 2003. Aprova as diretrizes para criação, reformulação, estruturação e funcionamento dos Conselhos de Saúde. Diário Oficial da União, Brasília, 4 nov. 2003.

BRASIL. Lei n. 8.080, de 19 de setembro de 1990. Dispõe sobre as condições para a promoção, proteção e recuperação da saúde, a organização e o funcionamento dos serviços correspondentes e dá outras providências. Diário Oficial da União, Brasília, 19 set. 1990a.

BRASIL. Lei n. 8.142, de 28 de dezembro de 1990. Dispõe sobre a participação da comunidade na gestão do Sistema Único de Saúde (SUS) e sobre as transferências intergovernamentais de recursos financeiros na área da saúde e dá outras providências. Diário Oficial da União, Brasília, 28 dez. 1990b.

BRAVO, M. I. S.; CORREIA, M. V. C. Desafios do controle social na atualidade. Serviço Social \& Sociedade, São Paulo, n. 109, p. 126-50, jan./mar. 2012.

COSTA, A. M.; VIEIRA, N. A. Participação e controle social em saúde. In: FUNDAÇÃO OSWALDO CRUZ. A saúde no Brasil em 2030 - prospecção estratégica do sistema de saúde brasileiro: organização e gestão do sistema de saúde. Rio de Janeiro: Fiocruz/Ipea/Ministério da Saúde/Secretaria de Assuntos Estratégicos da Presidência da República, 2013.

CURITIBA. Regimento Interno Conselho Municipal de Saúde de Curitiba. Aprovado na 12a Reunião Extraordinária do Conselho Municipal de Saúde de Curitiba, 24 de novembro de 2015. Disponível em: http://www.saude.curitiba.pr.gov.br/images/Regimento\%20Interno\%20CMS\%20aprovado\%20em\%20 24.11.2015.pdf. Acesso em: 20 fev. 2016.

CURITIBA. Câmara Municipal de Curitiba. Lei n. 7.631, de 17 de abril de 1991. Autoriza a constituição da conferência municipal da saúde e do conselho municipal da saúde e dá outras providências. Diário Oficial Municipal, Curitiba, 17 abr. 1991.

DITTERICH, R. G.; MOYSÉS, S. T.; MOYSÉS, S. J. O uso de contratos de gestão e incentivos profissionais no setor público da saúde. Cadernos de Saúde Pública, Rio de Janeiro, v. 28, n. 4, p. 615-27, abr. 2012.

ESCOVAL, A. O processo de contratualização na saúde em Portugal (1996-2005). Revista Portuguesa de Saúde Pública, n. 9, p. 7-24, 2010.

GOHN, M. G. O protagonismo da sociedade civil. Movimentos sociais, ONGs e redes solidárias. São Paulo: Cortez, 2005.

LOPES, B. J.; SILVA, E. A.; MARTINS, S. Conselho Municipal de Saúde sob a ótica de seus conselheiros: estudo realizado em uma capital brasileira. Interações, Campo Grande, MS, v. 17, n. 2, p. 163-72, abr./jun. 2016.

MARTY, I. K. Contratos de gestão na SMS - Curitiba (Responsabilização pactuada com o nível local). 2012. Disponível em: http://cosemspb.org/wp-content/uploads/2012/04/CTBA_Contratos_de_gestao_na_ SMS_Curitiba_-_-Ines_Marty.pdf. Acesso em: 20 fev. 2016. 
MARTY, I. K. Primeiras experiências de contratos de gestão em Curitiba: Secretaria Municipal da Saúde. In: GIACOMINI, C. H. Gestão para resultados em Curitiba: a experiência de contratualização. Curitiba: Instituto Municipal de Administração Pública, 2009.

NOGUEIRA, F. C. P. et al. Implantação de um conselho local de saúde: desafios da prática do controle social. Revista Baiana de Saúde Pública, Salvador, BA, v. 32, n. 1, p. 104-10, 2008.

ROLIM, L. B.; CRUZ, R. S. B. L. C.; SAMPAIO, K. J. A. J. Participação popular e o controle social como diretriz do SUS: uma revisão narrativa. Saúde em Debate, Rio de Janeiro, v. 37, n. 96, p. 139-47, jan./mar. 2013.

SALIBA, N. A. et al. Conselhos de saúde: conhecimento sobre as ações de saúde. Revista de Administração Pública, Rio de Janeiro, v. 43, n. 6, p. 1369-78, nov./dez. 2009.

SMITH, G. Democratic innovations: designing institutions for citizen participation. Cambridge: Cambridge University Press, 2009.

TAVARES, F. A. et al. Novas perspectivas na gestão para resultados na saúde em Minas Gerais: a implantação dos contratos organizativos de ação pública de saúde. In: CONGRESSO CONSAD DE GESTÃO PÚBLICA, 6., 2013, Brasília. Anais [...]. Brasília, 2013. p. 1-21. Disponível em: http://consadnacional.org. br/wp-content/uploads/2013/05/031-NOVAS-PERSPECTIVAS-NA-GEST\%C3\%83O-PARA-RESULTADOS-NASA\%C3\%9ADE-EM-MINAS-GERAIS-A-IMPLANTA\%C3\%87\%C3\%830-DOS-CONTRATOS-ORGANIZATIVOSDE-A\%C3\%87\%C3\%830-P\%C3\%9ABLICA-DE-SA\%C3\%9ADE.pdf

TORRES, M. D. F. Agências, contratos e OSCIPS. Rio de Janeiro: Editora FGV, 2007.

WORLD BANK. Brazil Enhancing Performance in Brazil's Health Sector: lessons from innovations in the state of São Paulo and the city of Curitiba. Washington: The World Bank, 2006.

\section{Sobre os autores:}

Thabata Cristy Zermiani: Mestre em Políticas Públicas e graduada em Odontologia pela Universidade Federal do Paraná (UFPR). E-mail: thabata.zermiani@gmail.com, Orcid: http://orcid.org/0000-0003-1542-7173

Rosane Souza Freitas: Mestre em Políticas Públicas pela Universidade Federal do Paraná (UFPR). Pós-graduada em Saúde Coletiva, na modalidade Residência Multiprofissional (UNIT/Secretaria de Saúde de Aracaju, SE). Graduada em Serviço Social pela Universidade Tiradentes (Aracaju, SE). E-mail: rosane_freitas@hotmail.com, Orcid: http://orcid.org/0000-0003-3491-5770 :

Huáscar Fialho Pessali: Doutor pela University of Hertfordshire. Professor do Programa de PósGraduação em Políticas Públicas da Universidade Federal do Paraná (UFPR). Pesquisador do CNPq. Coordena na UFPR o Núcleo de Estudos em Instituições (NINST) e o Observatório dos Conselhos. Seus trabalhos no campo das políticas públicas se voltam a temas como desenho institucional, papel das instituições, e instituições de democracia participativa. E-mail: pessali@ufpr.br, Orcid: http://orcid.org/0000-0002-5770-4653

Rafael Gomes Ditterich: Doutor em Odontologia (Saúde Coletiva) pela Pontifícia Universidade Católica do Paraná (PUCPR). Professor Adjunto do Departamento de Saúde Coletiva; ViceCoordenador do Curso de Odontologia; Professor do Programa de Pós-Graduação em Políticas Públicas e do Mestrado em Saúde Coletiva da Universidade Federal do Paraná. E-mail: prof.rafaelgd@gmail.com, Orcid: http://orcid.org/0000-0001-8940-1836 